\title{
The epidemiology of dependency among urban-dwelling older people in the Dominican Republic; a cross-sectional survey Daisy Acosta*1, Ruth Rottbeck ${ }^{2}$, Guillermina Rodríguez ${ }^{3}$, Cleusa P Ferri ${ }^{4}$ and Martin J Prince ${ }^{4}$
}

\begin{abstract}
Address: ${ }^{1}$ Internal Medicine Department, Geriatric Section, Universidad Nacional Pedro Henriquez Ureña (UNPHU), Santo Domingo, Dominican Republic, ${ }^{2}$ Charité Universitätsmedizin Berlin, Freie Universität and Humboldt Universität Berlin, Germany, ${ }^{3}$ Dirección General de Salud Pública. Ministerio de Protección Social (6th District), Santo Domingo, Dominican Republic and ${ }^{4}$ Section of Epidemiology, Health Service and Population Research Department, Institute of Psychiatry, King's College London, London, UK

Email: Daisy Acosta* - daisyacosta@codetel.net.do; Ruth Rottbeck - ruth.rottbeck@googlemail.com; Guillermina Rodríguez - daisyacosta@codetel.net.do; Cleusa P Ferri - cleusa.ferri@iop.kcl.ac.uk; Martin J Prince - m.prince@iop.kcl.ac.uk

* Corresponding author
\end{abstract}

Published: 13 August 2008

BMC Public Health 2008, 8:285 doi:10.1 186/147|-2458-8-285

This article is available from: http://www.biomedcentral.com/I47I-2458/8/285

(C) 2008 Acosta et al; licensee BioMed Central Ltd.

This is an Open Access article distributed under the terms of the Creative Commons Attribution License (http://creativecommons.org/licenses/by/2.0), which permits unrestricted use, distribution, and reproduction in any medium, provided the original work is properly cited.
Received: 25 February 2008

Accepted: 13 August 2008

\begin{abstract}
Background: Demographic ageing, and the health transition will soon lead to large increases in the number of dependent older people in low and middle income countries. Despite its importance, this topic has not previously been studied.

Methods: A cross sectional catchment area one-phase survey of health conditions, dependency, care arrangements and caregiver strain among $201 \mathrm{I}$ people aged 65 years and over in Santo Domingo, Dominican Republic

Results: $7.1 \%$ of participants required much care and a further $4.7 \%$ required at least some care. The prevalence of dependency increased sharply with increasing age. Dependent older people were less likely than others to have a pension and much less likely to have paid work, but no more likely to benefit from financial support from their family. Needing much care was strongly associated with comorbidity between cognitive, psychological and physical health problems. However, dementia made the strongest independent contribution. Among those needing care, those with dementia stood out as being more disabled, as needing more care (particularly support with core activities of daily living), and as being more likely to have paid caregivers. Dementia caregivers experienced more strain than caregivers of those with other health conditions, an effect mediated by behavioural and psychological symptoms.
\end{abstract}

Conclusion: Dependency among older people is nearly as prevalent in Dominican Republic as in developed western settings. Non-communicable diseases, particularly dementia are the main contributing factors. Attention needs to be directed towards the development of age-appropriate healthcare, a long-term care policy, and mechanisms for ensuring the social protection of older persons. 


\section{Background}

In the world's developing regions people are living longer, and having fewer children. High fat diets, smoking and sedentary lifestyles are becoming more common. Chronic non-communicable diseases (NCDs) linked to ageing heart disease, stroke, cancer and dementia - are much more in evidence, and beginning to be recognized as a public health priority [1]. While cancer and heart disease contribute mainly to mortality, much of the burden of other NCDs (dementia, mental disorders, diabetes and stroke) arises instead from years lived with disability)[2]. Chronic disability, and the conditions that contribute to it have received comparatively little attention, in research, policy or practice.

Disability, as defined by the World Health Organization (WHO), refers to difficulties in carrying out an activity due to increased effort, discomfort or pain, slowness or changes in the way the activity is performed. Dependency, defined as 'the requirement for frequent help from other people, beyond what would be expected by virtue of family or social ties' [3] stems from disability, but disability may occur without dependency.

Estimates from the WHO Global Burden of Disease project (where both disability levels and needs for care were inferred from diagnoses) suggest that the total population prevalence of dependency is similar worldwide, varying only from $4.4 \%$ to $5.1 \%$ by region, and will increase only marginally by 2050 [4]. However, this overall stability masks a substantial shift in the profile of dependency, occurring mainly in low and middle income countries (LAMIC), and linked both to rapid demographic ageing and the health transition. The proportions of dependent persons who are aged 60 and over will increase between 2000 and 2050, from $21 \%$ to $30 \%$ in sub-Saharan Africa, from $23 \%$ to $44 \%$ in India, from $23 \%$ to $47 \%$ in Latin America, from $30 \%$ to $60 \%$ in China, and from $45 \%$ to $61 \%$ in developed countries [5]. Over this period numbers of dependent older people are forecast to quadruple in most LAMIC, while numbers of dependent younger people remain relatively stable. Therefore, in all world regions dependency is rapidly becoming a problem associated with ageing processes, particularly non-communicable disease morbidity.

Dependency is an important outcome for policy and practice. Dependent older people need care and support, which, typically, means a family member, friend or neighbour. This support may or may not be forthcoming. Caregivers can be tied to their role, with little or no respite. In developed countries caregiving is consistently associated with role strain and a high prevalence of anxiety and depression [6]. There is also accumulating evidence of adverse effects on caregiver health [7] including increased mortality [8]. 10/66 Dementia Research Group pilot studies in 24 LAMIC centres indicated that in the absence of formal support services dementia caregivers often have to cut back on paid work to care or face the costs of hiring paid help [9]. There are no compensatory benefits [9]. Since dependent older people often live in multigenerational households with their caregiver and their caregiver's children, caregiver psychological and financial strain could have wider negative impacts on, for example, child health and development, retention in education, and poverty prevention.

The 10/66 Dementia Research Group has conducted comprehensive population-based cross-sectional surveys of catchment areas in ten developing countries (India, China, Nigeria, Cuba, Brazil, Venezuela, Mexico, Peru, Argentina and the Dominican Republic) [10]. This new resource will allow us to estimate the prevalence of dependency, and the relative contribution of different NCDs to needs for care in the general older population. We are also now able to characterise care arrangements for people with dementia in representative population-based samples, comparing and contrasting these with those needing care in the context of other health conditions. This report focuses on a survey of five catchment area districts in Santo Domingo, the capital of the Dominican Republic.

\section{Methods}

The Dominican Republic shares the Caribbean island of Hispaniola with Haiti. The population is 9.4 million, and 0.5 million (5.7\%) are aged 65 and over [11]. Life expectancy is 71 years for men and 75 for women. The Dominican Republic is one of the poorest of the 10/66 Latin American countries, with a per capita GDP (PPP) of US\$ 9,200 . In common with other countries in the region there are high levels of income inequality (a Gini index of 51.6). Forty two percent of the population live below the poverty line, one third of these in extreme poverty. Pension coverage, at only $18 \%$ of the economically active population, is one of the lowest in Latin America. Extensive reforms have been proposed, and are in the process of implementation. Community health care is provided by the government through the system of 'primary attention units'. Consultations are free, but medicines must be paid for. Despite low medical insurance coverage, private healthcare is widely used instead. The Dominican Republic has only twenty psychiatrists, twenty psychologists, and two neurologists per million population.

Study design and catchment area: A one-phase cross-sectional whole population catchment area survey in geographically defined districts in Santo Domingo. The survey protocol is described in detail in an open access publication [10]. Precision calculations indicated that an 
overall sample of 2,000 would allow estimation of a typical dementia prevalence of $2.5 \%$ with a precision of \pm $0.9 \%$. Atypical middle-class or high-income areas were avoided. The catchment areas selected were Villa Francisca, San Carlos, San Antón, Mejoramiento Social and Santa Barbara. After defining the boundaries, mapping was carried out to identify and locate households. Possible participants (inclusion criterion age 65 and over) were identified. Age was formally determined on revisit for the interview by comparing stated age according to participant and informant, and official records if available. Irreconcilable discrepancies of three or more years were settled using an event calendar approach. Participants were recruited following informed consent or on the basis of a relative's agreement in case of lack of capacity for consent due to dementia. Interviews were carried out in participants' own homes. All participants received the full assessment lasting approximately two to three hours. Ethical approval for the survey was provided by the research ethics committee for the Institute of Psychiatry, King's College London, and the Bioethics National Committee for Research in the Dominican Republic.

\section{Measures}

I) Outcome - dependency

The interviewer used a series of open ended questions in their interview with a key informant, to establish the presence or absence of dependency:

a) Who shares the home with the participant?

b) What kind of help does the participant need - inside of the home? - outside of the home?

c) Who, in the family, is available to care for the participant?

d) What help do you provide?

e) Do you help to organise care and support for the participant?

f) Is there anyone else in the family who is more involved in helping than you? What do they do? What about friends and neighbours? What do they do?

On the basis of the answers to these questions, the interviewer defined the family network, established if the older person needed and got any care from family members or others, identified who was responsible for organising and providing 'hands on' care, and if the informant was one of the main caregivers. Finally, they coded whether the older person required a) no care, b) care, some of the time or c) care, much of the time.

\section{2) Health conditions contributing to dependency}

a) Dementia according to either the $10 / 66$ dementia diagnosis algorithm [12] or DSM IV dementia criterion [13].

b) Physical illness. Self-reported stroke, and having three or more of 11 limiting physical impairments (arthritis or rheumatism; eyesight problems; hearing difficulty or deafness; persistent cough; breathlessness, difficulty breathing or asthma; high blood pressure; heart trouble or angina; stomach or intestine problems; faints or blackouts; paralysis, weakness or loss of one leg or arm; skin disorders such as pressure sores, leg ulcers or severe burns) [14]

c) Depression - ICD 10 depressive episode (mild, moderate or severe), derived using a computerised algorithm applied to a structured clinical interview, the Geriatric Mental State [15].

\section{3) Characterisation of those with dependency}

a) Disability Activity limitation and participation restriction measured by the WHO-DAS II [16], specifically developed by the WHO as a culture-fair assessment tool for use in cross-cultural comparative epidemiological and health services research.

b) Care arrangements (only assessed among those needing care)

Time spent by the caregiver in the last 24 hours in specific caregiving activities [17]; communicating, using transport, dressing, eating, looking after one's appearance, and supervising,

c) Impact of providing care on caregivers (only assessed among those needing care)

Caregiver perceived strain - the Zarit Burden Interview [18-20] with 22 items that assess the caregiver's appraisal of the impact their involvement has had on their lives.

Economic strain - the extent to which the caregiver had cut back on or stopped work in order to provide care, and paid care inputs

d) Caregiver mental health - the Self Reporting Questionnaire $20[21,22]$.

e) Behavioural and Psychological symptoms of dementia; the Neuropsychiatric Inventory, NPI-Q [23].

The assessments of care arrangements and caregiver strain were applied and refined in the previous 10/66 Dementia Research Group pilot studies, conducted in 26 LAMIC centres, including the Dominican Republic. The Zarit Burden Interview was found to have robust cross-cultural 
measurement properties $[9,24]$, but has not been specifically validated for this population. The NPI-Q has been previously validated in Spanish [25], but we are not aware of any previous use in the Dominican Republic.

\section{Analyses}

1) We report the prevalence of dependency (needing some care, needing much care, needing any care) by age and gender using Stata 9.2 survey commands to generate robust standard errors and 95\% confidence intervals, taking account of household clustering.

2) We describe the sociodemographic characteristics, economic circumstances and health status of the sample by levels of dependency. We used a Poisson regression model (adjusted for household clustering) to estimate the independent associations of dementia, three or more physical impairments, stroke and ICD-10 depression with needing much care, controlling for age, gender, education and marital status. The resulting prevalence ratios, together with the prevalence of the exposure were used (STATA aflogit command) to calculate population attributable prevalence fractions (PAPFs) as an index of the salience of each health condition to the prevalence of dependency at the population level.

3) Among those needing care, we compare the health characteristics, care inputs, and indicators of caregiver strain between those with dementia (and their caregivers) and those with other health conditions (and their caregivers).

4) We generated a general linear model to estimate the independent contributions of dementia, depression, physical impairments and stroke to caregiver strain measured using the Zarit Burden Interview, controlling for the main sociodemographic characteristics of the care recipient and the caregiver, and their relationship. The proportion of the variance accounted for by these factors was estimated before and after adding, separately, time spent assisting with activities of daily living, and the severity of behavioural and psychological symptoms in the care recipient as potential mediating variables in the association between dementia and caregiver strain.

\section{Results}

\section{Sample characteristics}

Door-knocking of the five catchment areas yielded 2117 persons eligible for the study; 2011 (95\%) provided informed consent and were interviewed. The principal characteristics of the participants are provided in Table 1. Their median age was 74.0 years (interquartile range 69.0 to 80 years, total range 65 to 104 years). Two thirds of the participants were female $(65.8 \%)$. The large majority $(70.3 \%)$ had not completed primary education. Living alone was unusual (12.6\%); most lived in two to four person households. Many were separated or divorced (23.1\%), with only $29.1 \%$ currently married.

\section{Prevalence of dependency}

Needs for care were identified in 237 participants (11.8\%), of whom 94 (4.7\%) were rated as needing some care and $143(7.1 \%)$ much care. Prevalence of all levels of dependency increased with age (see Table 2), linearly for men, and exponentially among women. The prevalence of dependency was higher among men at younger ages, and among women in those over 80 years old.

\section{Correlates of dependency}

Those with dependency needs were older, more likely to be female and widowed (Table 1). However, they were also less likely to be living alone and had a higher median household size. They had generally lower levels of education and (a non-significant trend) fewer household assets. Almost one in 10 of the whole sample, but only one dependent participant, continued to work. Dependent older people were also less likely to receive a government or occupational pension, but were no more likely than others to benefit from financial support from their family. Only six $(2.5 \%)$ of those needing care were in receipt of a disability pension.

\section{Associations between impairments, diagnoses, disability and dependency}

People with dementia accounted for 82 (57.3\%) of those needing much care and $23(24.5 \%)$ of those needing some care (Table 3 ). Other pathologies also clustered in the group needing much care - 72 (50.3\%) had three or more limiting physical impairments, 49 (34.3\%) had a current depressive episode and 42 (29.4\%) reported having had a stroke. Evidently there was considerable comorbidity within this group, and comorbidity was strongly associated with needing higher levels of care. Dependency was very strongly associated with high levels of disability, and poor self-reported health.

Poisson regression across the whole sample, adjusting for participant age, gender, education and marital status revealed that dementia (Prevalence Ratio 5.21, 95\% confidence intervals 3.64-7.47), major depression (PR 1.88, 95\% CI 1.31-2.69), stroke (PR 2.04, 95\% CI 1.43-2.89) and physical illness (PR 2.18, 95\% CI 1.58-3.01) were independently associated with needing much care. Population attributable prevalence fractions (the proportion of prevalent needs for care that might have been avoided had the condition been prevented) were for dementia 0.44 , for physical illness 0.43 (stroke 0.16 , three or more physical illnesses 0.27 ) and depression 0.16. 
Table I: General characteristics of the sample, by dependency status

\begin{tabular}{|c|c|c|c|c|c|c|}
\hline & & $\begin{array}{l}\text { Total sample } \\
N=2011 \\
N(\%)\end{array}$ & $\begin{array}{l}\text { Dependent (needs } \\
\text { care some or much } \\
\text { of the time) } \\
N=237 \\
N(\%)\end{array}$ & $\begin{array}{l}\text { Not dependent } \\
\text { (does not need care) } \\
N=1864 \\
N(\%)\end{array}$ & Statistical test & $\mathrm{p}$-value \\
\hline \multirow[t]{4}{*}{ Age } & $65-69$ years & $533(26.5 \%)$ & 17 (7.2\%) & $514(29.0 \%)$ & $\chi^{2}=125.8(I \mathrm{df})$ & $<0.001$ \\
\hline & 70-74 years & $520(25.9 \%)$ & 41 (17.3\%) & $478(27.0 \%)$ & & \\
\hline & $75-79$ years & $397(19.7 \%)$ & 37 (15.6\%) & $360(20.3 \%)$ & & \\
\hline & $80+$ years & $56 \mid(27.9 \%)$ & $142(59.9 \%)$ & $418(23.6 \%)$ & & \\
\hline Gender & Female & $1324(65.8 \%)$ & $173(70.0 \%)$ & $1149(65.0 \%)$ & $\chi^{2}=6.0(\mathrm{l} \mathrm{df})$ & 0.02 \\
\hline \multirow[t]{5}{*}{ Education } & None & $392(19.5 \%)$ & $61(26.9 \%)$ & $331(18.8 \%)$ & $\chi^{2}=4.5(\mathrm{I} d f)$ & 0.03 \\
\hline & Some & $1022(50.8 \%)$ & $113(49.8 \%)$ & 907 (51.5\%) & & \\
\hline & completed primary & $370(18.4 \%)$ & $32(14.1 \%)$ & $336(19.1 \%)$ & & \\
\hline & Completed secondary & $135(6.7 \%)$ & $10(4.4 \%)$ & $125(7.1 \%)$ & & \\
\hline & completed tertiary & $73(3.6 \%)$ & II (4.8\%) & $62(3.5 \%)$ & & \\
\hline \multirow[t]{4}{*}{ Marital status } & Never married & $139(6.9 \%)$ & $14(6.0 \%)$ & $125(7.1 \%)$ & $\chi^{2}=16.6(3 \mathrm{df})$ & 0.001 \\
\hline & Married & $586(29.1 \%)$ & $49(21.0 \%)$ & $534(30.4 \%)$ & & \\
\hline & Widowed & $806(40.1 \%)$ & $122(52.4 \%)$ & $683(38.8 \%)$ & & \\
\hline & Divorced & $465(23.1 \%)$ & $48(20.6 \%$ & $417(23.7 \%)$ & & \\
\hline Lives alone & & $254(12.7 \%)$ & $13(5.5 \%)$ & $24 I(13.6 \%)$ & $\chi^{2}=12.5(1 \mathrm{df})$ & $<0.001$ \\
\hline Household size & $\begin{array}{l}\text { Median } \\
\text { (interquartile range) }\end{array}$ & $2(1-4)$ & $3(I-5)$ & $2(I-4)$ & $Z=-3.1$ & 0.002 \\
\hline \multirow[t]{4}{*}{$\begin{array}{l}\text { Sources of income } \\
\text { (not mutually exclusive) }\end{array}$} & $\begin{array}{l}\text { Government or } \\
\text { occupational pension }\end{array}$ & $610(30.4 \%)$ & 57 (24.1\%) & $553(31.2 \%)$ & $\chi^{2}=5.1(I d f)$ & 0.02 \\
\hline & Family transfers & $582(29.0 \%)$ & 65 (27.4\%) & $517(29.2 \%)$ & $\chi^{2}=0.3(I d f)$ & 0.57 \\
\hline & Disability pension & $8(0.4 \%)$ & $6(2.5 \%)$ & $2(0.1 \%)$ & $\chi^{2}=30.8(1 \mathrm{df})$ & $<0.001$ \\
\hline & Paid work & $165(8.2 \%)$ & I $(0.4 \%)$ & $163(9.4 \%)$ & $\chi^{2}=21.7(1 \mathrm{df})$ & $<0.001$ \\
\hline \multirow[t]{4}{*}{ Household assets } & | st quarter - least & $648(32.2 \%)$ & $87(36.7 \%)$ & $559(31.6 \%)$ & $\chi^{2}=12.5(\mathrm{l} d \mathrm{df})$ & 0.097 \\
\hline & $2^{\text {nd }}$ quarter & $444(22.1 \%)$ & $51(21.5 \%)$ & $392(22.1 \%)$ & & \\
\hline & $3^{\text {rd }}$ quarter & $733(36.4 \%)$ & $81(34.2 \%)$ & 651 (36.8\%) & & \\
\hline & $4^{\text {th }}$ quarter - most & $186(9.2 \%)$ & $18(7.6 \%)$ & $168(9.5 \%)$ & & \\
\hline
\end{tabular}

\section{The caregivers}

For 214 of the 237 participants needing care (90.7\%), the informant identified them self as the main caregiver; 190 $(80.5 \%)$ were the main 'hands on' caregivers and 24 $(10.2 \%)$ the main organisational caregivers. The largest group, 107 (45.2\%), were children or children-in-law of the care recipient, 42 (17.7\%) were spouses, 54 (22.8\%) were other relatives, and $34(14.4 \%)$ were friends or neighbours. One hundred and ninety $(80.2 \%)$ of the caregivers were female, and 63 (26.5\%) were in full or parttime employment. One hundred and three of the care recipients shared their household with one or more child under the age of 16 years $(43.5 \%)$. None of these characteristics varied significantly between those with and without dementia.

\section{Dementia and dependency}

Among those needing care, those with dementia had higher levels of disability and were more likely to need much care than others with dependency needs but no dementia (see Table 4). They were as likely to have three or more limiting physical illnesses and more likely to have reported a previous stroke. Their caregivers spent more time on general supervision and on assisting with basic activities of daily living - dressing, eating, bathing, toileting and grooming. Daytime and night time paid help was more likely to be required, but with borderline statistical significance. Caregivers of those with dementia experienced significantly more caregiver strain according to the Zarit Burden Interview.

\section{Correlates of caregiver strain}

We constructed a multivariate model examining the effects of dementia, depression and physical illness on caregiver strain, controlling for participant age, gender, education and marital status, and for the age, gender, marital status, relationship to participant and residence of the caregiver. Complete data was available for 195 of the 237 care recipient/caregiver dyads. Only dementia and age of participant (more strain in caregivers of younger participants) were associated with caregiver strain. In the fully adjusted model, dementia accounted for $6.9 \%$ of the variance in caregiver strain $(\mathrm{F}=11.9, \mathrm{p}=0.001)$, depression $0.8 \%(\mathrm{~F}=1.4, \mathrm{p}=0.25)$ and three or more physical impairments $0.5 \%(\mathrm{~F}=0.9, \mathrm{p}=0.36)$. Including time spent assisting with activities of daily living in the model (as a potential mediating factor) marginally attenuated the strength of the association with dementia. Time spent 
Table 2: Prevalence (\%) of needs for care with $95 \%$ confidence intervals, by age and gender

\begin{tabular}{|c|c|c|c|c|c|}
\hline & $65-69$ & $70-74$ & $75-79$ & $80+$ & Total \\
\hline \multicolumn{6}{|l|}{ No care } \\
\hline \multirow[t]{2}{*}{ Women } & $97.4[95.0,98.6]$ & $\begin{array}{l}91.6[88.1,94.2] \\
91.7\end{array}$ & $92.1[88.2,94.8]$ & $70.4[65.7,74.7]$ & $86.9[85.0,88.6]$ \\
\hline & $\mathrm{n}=334$ & $n=296$ & $\mathrm{n}=244$ & $n=276$ & $\mathrm{n}=1150$ \\
\hline Men & $\begin{array}{l}95.7[91.7,97.9] \\
n=179\end{array}$ & $\begin{array}{l}92.8[88.2,95.7] \\
n=|8|\end{array}$ & $\begin{array}{l}87.9[81.1,92.4] \\
n=116\end{array}$ & $\begin{array}{l}84.5[78.2,89.3] \\
n=142\end{array}$ & $\begin{array}{l}90.6[88.2,92.6] \\
n=618\end{array}$ \\
\hline Total & $\begin{array}{l}96.8[94.9,98.0] \\
n=514\end{array}$ & $\begin{array}{l}92.1[89.5,94.1] \\
n=478\end{array}$ & $\begin{array}{l}90.7[87.4,93.2] \\
\mathrm{n}=360\end{array}$ & $\begin{array}{l}74.6[70.9,78.1] \\
n=418\end{array}$ & $\begin{array}{l}88.2[86.7,89.5] \\
n=1770\end{array}$ \\
\hline \multicolumn{6}{|c|}{ Some care } \\
\hline Women & $\begin{array}{l}0.9[0.3,2.7] \\
n=3\end{array}$ & $\begin{array}{l}4.0[2.3,6.8] \\
n=13\end{array}$ & $\begin{array}{l}3.8[2.0,6.9] \\
n=10\end{array}$ & $\begin{array}{l}10.5[7.7, \mid 4.0] \\
n=4 \mid\end{array}$ & $\begin{array}{l}5.1[4.0,6.4] \\
n=67\end{array}$ \\
\hline Men & $\begin{array}{l}2.1[0.8,5.6] \\
n=4\end{array}$ & $\begin{array}{l}2.6[1.1,6.0] \\
n=5\end{array}$ & $\begin{array}{l}3.8[1.6,8.8] \\
n=5\end{array}$ & $\begin{array}{l}7.7[4.5,12.9] \\
n=13\end{array}$ & $\begin{array}{l}4.0[2.7,5.7] \\
n=27\end{array}$ \\
\hline Total & $\begin{array}{l}\mathrm{I} .3[0.6,2.7] \\
\mathrm{n}=7\end{array}$ & $\begin{array}{l}3.5[2.2,5.4] \\
\mathrm{n}=18\end{array}$ & $\begin{array}{l}3.8[2.3,6.2] \\
n=15\end{array}$ & $\begin{array}{l}9.6[7.4,12.4] \\
n=54\end{array}$ & $\begin{array}{l}4.7[3.8,5.7] \\
n=94\end{array}$ \\
\hline \multicolumn{6}{|c|}{ Much care } \\
\hline Women & $\begin{array}{l}1.7[0.8,3.8] \\
n=6\end{array}$ & $\begin{array}{l}4.3[2.6,7.2] \\
n=14\end{array}$ & $\begin{array}{l}4.2[2.3,7.3] \\
n=I I\end{array}$ & $\begin{array}{l}19.1[15.6,23.3] \\
n=75\end{array}$ & $\begin{array}{l}8.0[6.7,9.6] \\
n=106\end{array}$ \\
\hline Men & $\begin{array}{l}2.1[0.8,5.6] \\
n=4\end{array}$ & $\begin{array}{l}4.6[2.4,8.6] \\
n=9\end{array}$ & $\begin{array}{l}8.3[4.7,14.4] \\
n=11\end{array}$ & $\begin{array}{l}7.7[4.5,12.9] \\
n=13\end{array}$ & $\begin{array}{l}5.4[4.0,7.4] \\
\mathrm{n}=37\end{array}$ \\
\hline Total & $\begin{array}{l}1.9[1.0,3.5] \\
\mathrm{n}=10\end{array}$ & $\begin{array}{l}4.4[3.0,6.6] \\
n=23\end{array}$ & $\begin{array}{l}5.5[3.7,8.3] \\
n=22\end{array}$ & $\begin{array}{l}15.7[12.9,19.0] \\
n=88\end{array}$ & $\begin{array}{l}7.1[6.1,8.3] \\
n=143\end{array}$ \\
\hline \multicolumn{6}{|c|}{ Any care (some or much) } \\
\hline Women & $\begin{array}{l}2.6[1.4,5.0] \\
\mathrm{n}=9\end{array}$ & $\begin{array}{l}8.4[5.8,11.9] \\
n=27\end{array}$ & $\begin{array}{l}7.9[5.2,11.9] \\
n=21\end{array}$ & $\begin{array}{l}29.6[25.3,34.3] \\
n=\mid 16\end{array}$ & $\begin{array}{l}13.1[1|.4,| 5.0] \\
n=173\end{array}$ \\
\hline Men & $\begin{array}{l}4.3[2.2,8.3] \\
\mathrm{n}=8\end{array}$ & $\begin{array}{l}7.2[4.3,1 \mid .8] \\
n=14\end{array}$ & $\begin{array}{l}12.1[7.6,18.9] \\
n=16\end{array}$ & $\begin{array}{l}\mid 5.5[|0.8,2| .8] \\
n=26\end{array}$ & $\begin{array}{l}9.4[7.4,11.8] \\
n=64\end{array}$ \\
\hline Total & $\begin{array}{l}3.2[2.0,5.1] \\
n=17\end{array}$ & $\begin{array}{l}7.9[5.9,10.5] \\
n=41\end{array}$ & $\begin{array}{l}9.3[6.8,12.6] \\
n=37\end{array}$ & $\begin{array}{l}25.4[21.9,29.1] \\
n=142\end{array}$ & $\begin{array}{l}11.8[10.5,13.3] \\
\mathrm{n}=237\end{array}$ \\
\hline
\end{tabular}

assisting with activities of daily living accounted for just $2.2 \%$ of the variance in caregiver strain $(\mathrm{F}=3.6, \mathrm{p}=0.06)$. Adding the severity of behavioural and psychological symptoms into the model abolished the association between dementia and caregiver strain. In the resulting model, behavioural and psychological symptoms alone accounted for $19.7 \%$ of the variance in caregiver strain ( $\mathrm{F}$ $=38.7, \mathrm{p}<0.001)$.

\section{Discussion and conclusion}

Surprisingly, this seems to be the first comprehensive, population-based study of dependency, and consequent care arrangements conducted in a low or middle income country. In Santo Domingo, 7.1\% of the older population (aged 65 years or older) required much care and a further $4.7 \%$ required at least some care. The prevalence of dependency increased sharply with increasing age, with the more marked dependency needs being concentrated among those aged 80 years and over. Income insecurity was prominent among dependent older people, who were less likely to be in receipt of a pension and much less likely to work, but no more likely to receive financial support from their family. Needing much care was strongly associated with comorbidity between cognitive, psychological and physical health problems. However, dementia made the strongest independent contribution to needing much care, with a population attributable prevalence fraction of 0.44. Among those needing care, those with dementia stood out as being more disabled, as needing more care (particularly support with core activities of daily living), and as being more likely to need the additional support of a paid caregiver. Carers of those with dementia experienced more role strain than did carers of those with other underlying health conditions. 
Table 3: Health status, by level of dependency

\begin{tabular}{|c|c|c|c|c|c|c|}
\hline & Needs much care & Needs some care & Does not need care & Whole sample & $\begin{array}{l}\text { Statistical tests for trend } \\
\text { (all I df) }\end{array}$ & $\mathrm{P}$-value \\
\hline \multicolumn{7}{|l|}{ Health Conditions } \\
\hline Dementia & $82(57.3 \%)$ & $23(24.5 \%)$ & 137 (7.7\%) & $242(12.1 \%)$ & $\chi^{2}=316.3$ & $<0.001$ \\
\hline $\begin{array}{l}\text { Three or more limiting physical } \\
\text { impairments }\end{array}$ & $72(50.3 \%)$ & 37 (39.4\%) & $355(20.1 \%)$ & $464(23.1 \%)$ & $\chi^{2}=81.9$ & $<0.001$ \\
\hline Stroke & $42(29.4 \%)$ & 14 (I4.9\%) & $119(6.7 \%)$ & 175 (8.7\%) & $\chi^{2}=88.4$ & $<0.001$ \\
\hline ICD 10 depressive episode & 49 (34.3\%) & $15(16.0 \%)$ & $214(12.1 \%)$ & $278(13.9 \%)$ & $\chi^{2}=51.4$ & $<0.001$ \\
\hline \multicolumn{7}{|l|}{ Comorbidity } \\
\hline None of the above & 15 (10.5\%) & $27(28.7 \%)$ & 1175 (66.4\%) & $1217(60.6 \%)$ & $\chi^{2}=312.3$ & $<0.001$ \\
\hline I only of the above & $48(33.6 \%)$ & 49 (52.1\%) & $400(22.6 \%)$ & $497(24.8 \%)$ & & \\
\hline 2 of the above & $50(35.0 \%)$ & 14 (14.9\%) & $160(9.1 \%)$ & $293(14.6 \%)$ & & \\
\hline 3 or more of the above & $30(21.0 \%)$ & $4(4.3 \%)$ & $33(1.9 \%)$ & 67 (3.3\%) & & \\
\hline \multicolumn{7}{|l|}{ Disability } \\
\hline $\begin{array}{l}\text { WHODAS II disability scale } \\
\text { score (mean/SD) }\end{array}$ & $58.2(22.0)$ & $33.0(18.4)$ & $12.3(15.4)$ & $16.5(20.3)$ & $\mathrm{F}=1168 \mathrm{Eta} s q=0.37$ & $<0.001$ \\
\hline \multicolumn{7}{|l|}{ Subjective health } \\
\hline Bad or very bad & $42(29.4 \%)$ & $12(12.8 \%)$ & $132(7.5 \%)$ & $186(9.2 \%)$ & $\chi^{2}=93.4$ & $<0.001$ \\
\hline
\end{tabular}

The strengths of our study are that we applied a one-phase survey methodology on a large representative sample of older adults, achieving a good response rate for a broad based assessment of health status (including cognitive, mental and physical disorders, global health and disability), social, demographic and economic circumstances. A suitable informant was interviewed for every participant to ascertain needs for care directly (as opposed to merely inferring this from participant reports of limitations in activities of daily living). In the event of the participant being identified as a care recipient, we obtained further detailed information on the care arrangements, and any consequent strain experienced by the caregiver. The main weakness is that dependency was ascertained using a semi-structured interview. The rating of level of dependency (some care versus much care) was somewhat subjective. This was intentional, given the difficulties of developing a more structured approach that would have had equal validity across many different countries and cultures. Nevertheless, data on inter-rater reliability would have been valuable. Also, dementia and depression were diagnosed on the basis of extensive structured clinical interviews whereas stroke and other physical impairments were assessed only on the basis of self-report. Therefore, there may have been greater misclassification of the physical health outcomes, possibly leading to an underestimation of their contribution to dependency. Conversely we did not specify, when screening for dependency, that care could include prompting, remembering and supervising, in addition to physical care. This might have led to an underestimation of the contribution of dementia to dependency.

Our estimate, of $11.8 \%$ of participants with dependency needs is a little lower than that from population-based surveys of those aged 65 and over from England and Wales [26] (15.7\% with significant disability among whom $86 \%$ had dependency needs), Scotland [27] (15\% with short interval dependency), Spain [28] (15.5\% with dependency in one or more of seven ADLs), France [29] (12.4\% confined to home or bed) and the USA National Long Term Care surveys [30] (17.1\% disabled in one or more activities of daily living, or living in a care home). Proper comparison would require age adjustment. Only the last of these studies provides age-specific prevalence estimates (65-74 8.4\%; 75-84 21.4\%; 85 and over $52.7 \%)$. Applying these prevalences to the age structure of our sample gives 377.5 expected cases of dependency versus the 237 that we observed, a standardised morbidity ratio of 62.8 .

People with dementia (often comorbid with other health conditions) accounted for more than half of those needing much care, and a quarter of those needing some care. Our findings regarding the particular character of the experiences linked to caring for an older person with 
Table 4: Characteristics of those needing care, care inputs and caregiver strain, by dementia status

\begin{tabular}{|c|c|c|c|c|c|}
\hline & $\begin{array}{l}\text { Those with dementia } \\
\text { needing care } N=105\end{array}$ & $\begin{array}{l}\text { Others needing } \\
\text { care } \mathrm{N}=132\end{array}$ & $\begin{array}{l}\text { All those needing } \\
\text { care } \mathrm{N}=237\end{array}$ & $\begin{array}{l}\text { Statistical tests (all I df } \\
\text { unless otherwise } \\
\text { specified) }\end{array}$ & $\mathrm{P}$-value \\
\hline \multicolumn{6}{|l|}{$\begin{array}{l}\text { Characteristics of those needing } \\
\text { care }\end{array}$} \\
\hline Three or more physical illnesses & 44 (4I.9\%) & 65 (49.2\%) & $109(46.0 \%)$ & $\chi^{2}=1.3$ & 0.26 \\
\hline Stroke & $36(34.3 \%)$ & $20(15.2 \%)$ & $56(23.6 \%)$ & $\chi^{2}=11.9$ & 0.001 \\
\hline ICD 10 depressive episode & $28(26.7 \%)$ & $36(27.3 \%)$ & $64(27.0 \%)$ & $\chi^{2}=0.0$ & 0.92 \\
\hline $\begin{array}{l}\text { WHODAS II disability scale score } \\
(\mathrm{mean} / \mathrm{SD})\end{array}$ & $57.3(25.3)$ & $41.0(20.3)$ & $48.2(24.0)$ & $\mathrm{T}=-5.4(194)$ & $<0.001$ \\
\hline $\begin{array}{l}\text { NPI-Q Behavioural and psychological } \\
\text { symptoms severity score (median/ } \\
\text { interquartile range) I MV }\end{array}$ & $10(5-17)$ & $5(2-9)$ & $7(3-12)$ & $Z=-5.4$ & $<0.001$ \\
\hline \multicolumn{6}{|l|}{ Care inputs } \\
\hline Needs much care & $82(78.1 \%)$ & $61(46.2 \%)$ & $143(60.3 \%)$ & $\chi^{2}=24.0$ & $<0.001$ \\
\hline \multicolumn{6}{|l|}{ Time per day spent supervising } \\
\hline 0 & 75 (7I.4\%) & $123(93.2 \%)$ & $198(83.5 \%)$ & $\chi^{2}=20.1$ & $<0.001$ \\
\hline $\mathrm{I}-5$ hours & $15(14.3 \%)$ & $9(6.8 \%)$ & $24(10.1 \%)$ & & \\
\hline 6 hours + & $15(14.3 \%)$ & $0(0 \%)$ & $15(6.3 \%)$ & & \\
\hline \multicolumn{6}{|l|}{$\begin{array}{l}\text { Time per day spent assisting with ADL } \\
\text { (\% spending more than one hour) }\end{array}$} \\
\hline Transport & $4(3.9 \%)$ & $9(6.8 \%)$ & $13(5.5 \%)$ & $\chi^{2}=0.03$ & 0.86 \\
\hline Dressing & $17(18.2 \%)$ & $11(8.3 \%)$ & $28(11.8 \%)$ & $\chi^{2}=20.5$ & $<0.001$ \\
\hline Eating & $21(20.0 \%)$ & $10(7.5 \%)$ & $31(13.0 \%)$ & $\chi^{2}=13.1$ & $<0.001$ \\
\hline Looking after appearance & $22(20.9 \%)$ & $13(9.8 \%)$ & 35 (14.7\%) & $\chi^{2}=7.7$ & 0.006 \\
\hline Toileting & $23(21.9 \%)$ & $10(8.6 \%)$ & $33(13.9 \%)$ & $\chi^{2}=21.4$ & $<0.001$ \\
\hline Bathing & 27 (25.8\%) & $9(6.8 \%)$ & $36(15.2 \%)$ & $\chi^{2}=30.2$ & $<0.001$ \\
\hline \multicolumn{6}{|l|}{ Caregiver strain indicators } \\
\hline $\begin{array}{l}\text { Caregiver psychological morbidity } \\
\text { (SRQ>8) }\end{array}$ & $32(30.5 \%)$ & $32(24.2 \%)$ & $64(27.0 \%)$ & $\chi^{2}=1.2$ & 0.28 \\
\hline Caregiver cut back on work to care & $33(31.4 \%)$ & 31 (23.5\%) & $64(27.0 \%)$ & $\chi^{2}=0.63$ & 0.43 \\
\hline $\begin{array}{l}\text { Caregiver Zarit Burden Interview score } \\
\text { (mean/SD) }\end{array}$ & $24.4(16.6)$ & $17.4(13.8)$ & $20.5(15.0)$ & $t=3.6(d f=232)$ & $<0.001$ \\
\hline Daytime paid help required & $24(22.9 \%)$ & $17(13.2 \%)$ & $4 \mathrm{I}(17.5 \%)$ & $\chi^{2}=3.7$ & 0.05 \\
\hline Night time paid help required & $18(17.1 \%)$ & $10(7.7 \%)$ & $28(12.0 \%)$ & $\chi^{2}=4.8$ & 0.03 \\
\hline Additional informal support required & $48(46.2 \%)$ & 49 (37.4\%) & $97(41.3 \%)$ & $\chi^{2}=1.5$ & 0.22 \\
\hline
\end{tabular}

dementia are consistent with the only comparable findings from a population based survey, that of more than 1,500 family caregivers interviewed in the 1996 USA National Caregiver Survey [31]. In the USA, dementia caregivers spent longer providing care, reported more impacts on their employment, more caregiver strain, more mental and physical health problems, less time for leisure and more family conflict. Unfortunately, dementia, which has a uniquely devastating impact on capacity for independent living is often forgotten when policies for prevention and management of NCDs are proposed, as for example with the recent Lancet Series on non-communicable diseases [32], and the WHO's Global Report on Innovative Care for Chronic Conditions [33]. An original finding from our analysis is that the effect of dementia upon caregiver strain is entirely mediated by the severity of behavioural and psychological symptoms. Furthermore the independent predictive power of these symptoms (19.6\% of the variance in caregiver strain explained) was much greater than that of dementia $(6.9 \%$ of the variance). Although often referred to as behavioural and psychological symptoms of dementia (BPSD) these features (psychological symptoms - delusions, hallucinations, depression/dysphoria, anxiety, elation/euphoria; behavioural symptoms - apathy, disinhibition, agitation/ aggression, motor, sleep and appetite disturbance) are not condition specific $[24,34]$. 
LAMIC governments will face many challenges in the near future as numbers of dependent older people increase rapidly. An adequate response will require

a) policies to prevent disability through the control of NCDs,

b) policies to limit disability through more active community-based rehabilitation,

c) policies to manage disability and dependency through improved access to age-appropriate long-term support and care.

Such measures are already strongly advocated through international agreements including the Madrid International Plan on Action on Ageing (2002) and the UN Convention on the Rights of People with Disabilities (2007). A recent WHO report on long-term care policy [35] noted wide international variation in the apportioning of responsibilities between families and the state, but proposed that all countries could and should determine transparently the assistance needed by older people and their carers, and the eligibility for and financing of longterm care support. In practice, LAMIC governments have avoided providing or financing long-term care [36], and few if any have comprehensive policies and plans.

Primary health care services in LAMIC tend to fail older people with dementia, [36-39] as they focus on acute 'treatable' conditions and are clinic-based. There is a need for a paradigm shift beyond simple curative interventions to encompass long-term regular support, community outreach and domiciliary care, family involvement and multisectoral working. The WHO have proposed an alternative care framework (Innovative Care for Chronic Conditions)[33] that addresses many of these issues. ICCC is likely to be as applicable to dementia care as to other chronic NCDs - mental disorders, stroke, heart disease and diabetes - for which it was initially proposed. $10 / 66$ is currently testing the effectiveness of training community healthcare workers to identify people with dementia [40-42], and to deliver a brief intervention to educate and train caregivers [10]. In practice, such interventions will need to be incorporated into horizontally constructed programs addressing the generic needs of frail, dependent older people and their caregivers, whether arising from cognitive, mental or physical disorders. One focus should perhaps be upon the assessment and syndromal management of the behavioural and psychological problems that, our research suggests, contribute so much to caregiver strain.

A key finding from our analysis is the economic disadvantage experienced by older dependent persons and the fam- ilies that care for them. For older people in developing countries 'dependency anxiety' $[37,43,44]$ - not wanting to be a burden on relatives, fearing inadequate support, and therefore wishing to maintain independence from the family - is a key motivating principle. The Nobel Prize winning economist Joseph Stiglitz commented:

'There is no subject of greater importance than the ageing of the population and the provision of social protection for older people. It affects the very nature of our societies and concerns not only older people, but all sections of the population.' [45].

Some LAMIC governments have sought to encourage or coerce families to shoulder this responsibility [36]. For example, the Indian parliament passed a law to this effect in 2007. Such policies seem destined to fail in the longerterm. Inexorable trends towards more internal and international migration, declining fertility, higher levels of education and increased participation of women in the workforce will reduce the availability and willingness of children (principally daughters and daughters-in-law) to care [36]. Social pensions provide insurance against the risks that older people face, including uncertainty over how long they will live, how long they will remain healthy, whether they can count upon the support of others if they need it, and how long they can earn an income. Furthermore, in rural Brazil, they have been shown to support whole families [46], reducing the risk of household poverty [47], and have even been linked to increased school enrolment, particularly of teenage girls [45]. Most importantly they reinforce reciprocal family ties, changing the perspective from one in which older people are seen as a dependent drain upon household resources to one in which they can be properly valued for their non-economic as well as their economic contributions. Dependent older people would be particularly likely to benefit - informal care would be bolstered and formal/paid care would be more affordable.

\section{Competing interests}

The 10/66 Dementia Research Group works closely with Alzheimer's Disease International (ADI), the non-profit federation of 77 Alzheimer associations around the world. ADI is committed to strengthening Alzheimer associations worldwide, raising awareness regarding dementia and Alzheimer's Disease and advocating for more and better services for people with dementia and their caregivers. ADI is supported in part by grants from GlaxoSmithKline, Novartis, Lundbeck, Pfizer and Eisai. DA is the Chair-elect of ADI.

\section{Authors' contributions}

MP conceived and performed the analysis and drafted the manuscript. RR assisted in the analysis and helped to draft 
the manuscript. DA, GR and CP participated in the design and coordination of the study and helped to draft the manuscript. All authors read and approved the final manuscript.

\section{Acknowledgements}

The 10/66 Dementia Research Group's research has been funded by the Wellcome Trust Health Consequences of Population Change Programme (GR066133 - Prevalence phase in Cuba and Brazil; GR08002 - Incidence phase in Peru, Mexico, Argentina, Cuba, Dominican Republic, Venezuela and China), the World Health Organisation (India, Dominican Republic and China), the US Alzheimer's Association (IIRG - 04 - 1286 - Peru, Mexico and Argentina), and FONDACIT (Venezuela). The Rockefeller Foundation supported our dissemination meeting at their Bellagio Centre. Alzheimer's Disease International has provided support for networking and infrastructure.

\section{References}

I. Fuster V, Voute J: MDGs: chronic diseases are not on the agenda. Lancet 2005, 366:15/2-15/4.

2. World Health Organisation: WHO Statistical Information System. Working paper describing data sources, methods and results for projections of mortality and burden of disease for 2005, 2015 and 2030. 2006.

3. Harwood RH: Commentary: Disability amongst elderly people world-wide: the need for multi-dimensional health assessment. Int J Epidemiol 2003, 32:988-989.

4. Harwood RH, Sayer AA, Hirschfeld M: Current and future worldwide prevalence of dependency, its relationship to total population, and dependency ratios. Bull World Health Organ 2004, 82:25I-258.

5. World Health Organisation: Current and future Caregiver Needs for People with Disabling Conditions. Geneva, WHO; 2002.

6. Schulz R, Martire LM: Family caregiving of persons with dementia: prevalence, health effects, and support strategies. Am J Geriatr Psychiatry 2004, I 2:240-249.

7. Schulz R, Newsom J, Mittelmark M, Burton L, Hirsch C, Jackson S: Health effects of caregiving: the caregiver health effects study: an ancillary study of the Cardiovascular Health Study. Ann Behav Med 1997, 19:I10-II6.

8. Schulz R, Beach SR: Caregiving as a risk factor for mortality: the Caregiver Health Effects Study. JAMA 1999, 282:2215-2219.

9. Prince $M$ : Care arrangements for people with dementia in developing countries. Int J Geriatr Psychiatry 2004, 19:170-177.

10. Prince M, Ferri CP, Acosta D, Albanese E, Arizaga R, Dewey M, Gavrilova SI, Guerra M, Huang Y, Jacob KS, Krishnamoorthy ES, McKeigue P, Rodrigues JL, Salas A, Sosa AL, Sousa R, Stewart R, Uwakwe $R$ : The protocols for the 10/66 Dementia Research Group population-based research programme. BMC Public Health 2007, 7:165.

II. Central Intelligence Agency: The World Factbook -- Dominican Republic. Washington DC, USA, CIA; 2008.

12. Prince M, Acosta D, Chiu H, Scazufca M, Varghese M: Dementia diagnosis in developing countries: a cross-cultural validation study. Lancet 2003, 361:909-917.

13. American Psychiatric Association: Diagnostic and Statistical Manual of Mental Disorders 4th edition. Washington DC, AMA; 1994.

14. George L K., Fillenbaum G G.: OARS methodology: A decade of experience in geriatric assessment. J Am Geriatr Soc 1985, 33(9):607-6I5.

15. Copeland JRM, Dewey ME, Griffith-Jones HM: A computerised psychiatric diagnostic system and case nomenclature for elderly subjects: GMS and AGECAT. Psychological Medicine 1986, 16:89-99.

16. Rehm J, Ustun TB, Saxena S: On the development and psychometric testing of the WHO screening instrument to assess disablement in the general population. International Journal of Methods in Psychiatric Research 2000, 8: I I 0-122.

17. Davis KL, Marin DB, Kane R, Patrick D, Peskind ER, Raskind MA, Puder KL: The Caregiver Activity Survey (CAS): develop- ment and validation of a new measure for caregivers of persons with Alzheimer's disease. Int J Geriatr Psychiatry 1997, I 2:978-988

18. Whitlatch C], Zarit SH, von Eye A: Efficacy of interventions with caregivers: a reanalysis. Gerontologist I991, 3 I:9-14.

19. Zarit SH, Reever KE, Bach-Peterson J: Relatives of the impaired elderly: correlates of feelings of burden. The Gerontologist 1980 20:649-655

20. Zarit SH, Todd PA, Zarit JM: Subjective burden of husbands and wives as caregivers: a longitudinal study. Gerontologist 1986, 26:260-266

21. Harpham T, Reichenheim M, Oser R, Thomas E, Hamid N, Jaswal S, Ludermir A, Aidoo M: Measuring mental health in a cost-effective manner. Health Policy Plan 2003, 1 8:344-349.

22. Beusenberg M, Orley J: User's guide to the Self Reporting Questionnaire. Geneva, World Health Organisation; 1994.

23. Kaufer DI, Cummings JL, Ketchel P, Smith V, MacMillan A, Shelley T, Lopez OL, DeKosky ST: Validation of the NPI-Q, a brief clinical form of the Neuropsychiatric Inventory. J Neuropsychiatry Clin Neurosci 2000, 12:233-239.

24. Ferri CP, Ames D, Prince M: Behavioral and psychological symptoms of dementia in developing countries. Int Psychogeriatr 2004, 16:44l-459.

25. Boada M, Cejudo JC, Tarraga L, Lopez OL, Kaufer D: [Neuropsychiatric inventory questionnaire (NPI-Q): Spanish validation of an abridged form of the Neuropsychiatric Inventory (NPI)]. Neurologia 2002, 17:317-323.

26. Melzer D, McWilliams B, Brayne C, Johnson T, Bond J: Profile of disability in elderly people: estimates from a longitudinal population study. BMJ 1999, 318: I 108-1 III

27. Bond J, Carstairs V: Services for the elderly: a survey of the characteristics and needs of a population of 5000 older people. London, HMSO; 1982.

28. Beland F, Zunzunegui MV: Predictors of functional status in older people living at home. Age Ageing 1999, 28: I53-I59.

29. Leibovici $D$, Curtis S, Ritchie K: The application of disability data from epidemiological surveys to the development of indicators of service needs for dependent elderly people. Age Ageing 1995, 24:14-20.

30. Manton KG, Corder L, Stallard E: Chronic disability trends in elderly United States populations: 1982-1 994. Proc Natl Acad Sci U SA 1997, 94:2593-2598.

3I. Ory MG, Hoffman RR III, Yee JL, Tennstedt S, Schulz R: Prevalence and impact of caregiving: a detailed comparison between dementia and nondementia caregivers. Gerontologist 1999 , 39:177-185

32. Strong K, Mathers C, Leeder S, Beaglehole R: Preventing chronic diseases: how many lives can we save? Lancet 2005, 366:1578-I582.

33. Epping-Jordan JE, Pruitt SD, Bengoa R, Wagner EH: Improving the quality of health care for chronic conditions. Qual Saf Health Care 2004, 13:299-305.

34. Lyketsos CG, Steinberg M, Tschanz JT, Norton MC, Steffens DC, Breitner JC: Mental and behavioral disturbances in dementia: findings from the Cache County Study on Memory in Aging. Am J Psychiatry 2000, 1 57:708-7|4.

35. World Health Organisation: Towards an International Consensus on Policy for Long-Term Care of the Ageing. Geneva, World Health Organization; 2000.

36. Prince M, Livingston $G$, Katona $C$ : Mental health care for the elderly in low-income countries: a health systems approach. World Psychiatry 2007, 6:5-13.

37. Patel $\mathrm{V}$, Prince M: Ageing and mental health in a developing country: who cares? Qualitative studies from Goa, India. Psychological Medicine 200 I, 3 I:29-38.

38. Shaji KS, Smitha K, Praveen Lal K, Prince M: Caregivers Of Patients With Alzheimer's Disease : A Qualitative Study From The Indian 10/66 Dementia Research Network. International Journal of Geriatric Psychiatry 2002, 18:1-6.

39. Dias A, Samuel R, Patel V, Prince M, Parameshwaran R, Krishnamoorthy ES: The impact associated with caring for a person with dementia: a report from the $10 / 66$ Dementia Research Group's Indian network. Int J Geriatr Psychiatry 2004, I 9: I 82-I84.

40. Shaji KS, Arun Kishore NR, Lal KP, Prince M: Revealing a hidden problem. An evaluation of a community dementia case-find- 
ing program from the Indian 10/66 dementia research network. International Journal of Geriatric Psychiatry 2002, 17:222-225.

4I. Ramos-Cerqueira AT, Torres AR, Crepaldi AL, Oliveira NI, Scazufca $M$, Menezes PR, Prince M: Identification of dementia cases in the community: a Brazilian experience. J Am Geriatr Soc 2005, 53:1738-1742.

42. Jacob KS, Senthil KP, Gayathri K, Abraham S, Prince MJ: Can health workers diagnose dementia in the community? Acta Psychiatr Scand 2007, I 1 6: 125-128.

43. Vatuk S: "To be a Burden on Others": Dependency Anxiety among the Elderly in India. In Divine Passions: The Social Construction of Emotion in India Edited by: Lynch OM. Berkeley, University of California Press; 1990:64-68.

44. Cohen L: Toward an anthropology of senility: anger, weakness, and Alzheimer's in Banaras, India. Med Anthropol Q 1995, 9:314-334

45. Gorman M: Age and Security - How social pensions can deliver effective aid to poor older people and their families. Help Age International; 2004.

46. Garcez-Leme LE, Leme MD, Espino DV: Geriatrics in Brazil: a big country with big opportunities. J Am Geriatr Soc 2005, 53:2018-2022.

47. Institute of Development and Policy Management/ HelpAge International: Non-contributory pensions and poverty prevention. A comparative study of Brazil and South Africa. Volume Final Report, DFID Project R7897, Pensions and Poverty Prevention. London, Institute of Development and Policy Management; 2003.

\section{Pre-publication history}

The pre-publication history for this paper can be accessed here:

http://www.biomedcentral.com/1471-2458/8/285/pre pub

Publish with Biomed Central and every scientist can read your work free of charge

"BioMed Central will be the most significant development for disseminating the results of biomedical research in our lifetime. "

Sir Paul Nurse, Cancer Research UK

Your research papers will be:

- available free of charge to the entire biomedical community

- peer reviewed and published immediately upon acceptance

- cited in PubMed and archived on PubMed Central

- yours - you keep the copyright

Submit your manuscript here:

http://www.biomedcentral.com/info/publishing_adv.asp
BiolMedcentral 